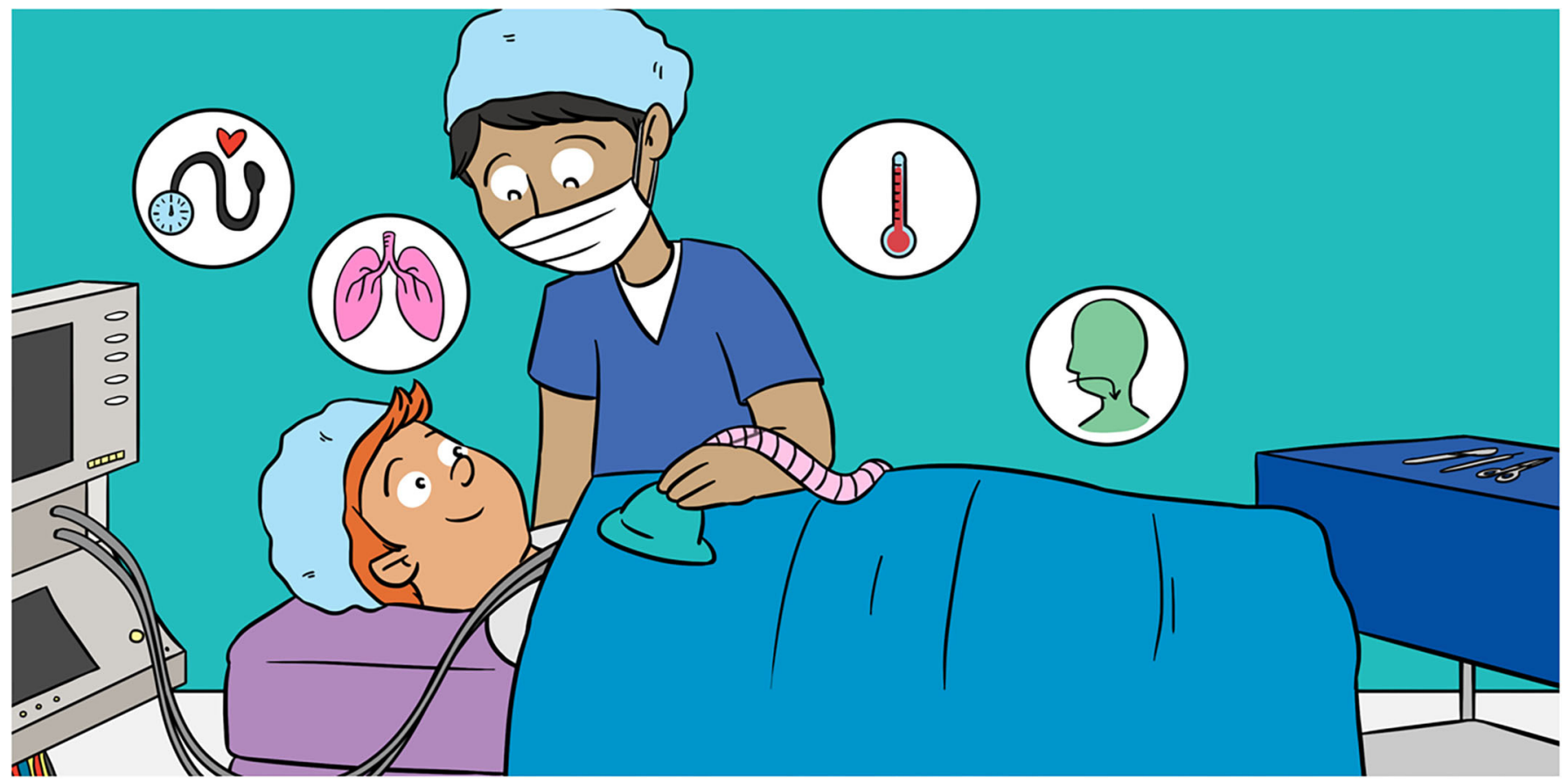

\title{
WHAT IS ANESTHESIA?
}

\section{Janna D. Lendner ${ }^{1,2 *}$}

${ }^{1}$ Helen Wills Neuroscience Institute, University of California, Berkeley, Berkeley, CA, United States

${ }^{2}$ Department of Anesthesiology and Intensive Care Medicine, University Medical Center Tuebingen, Tuebingen, Germany

YOUNG REVIEWER:

MARCEL

AGE: 10
Have you ever had surgery? If yes, perhaps you remember how you talked to the hospital staff before the operation, until everything suddenly became black? And when you woke up later, the operation was already finished, and you felt as if you had been asleep? But you were not asleep-you were under anesthesia, a drug-induced state in which you are not aware of your surroundings, do not feel any pain, and cannot move or form memories. Did you know that anesthesia was only discovered 150 years ago? Just imagine how traumatic an operation would have been when there was no anesthesia: people had to go through a surgery wide awake and with no pain killers! Luckily, nowadays we can feel at ease before an operation, knowing we will not experience it or feel any pain-thanks to anesthesia. But what exactly is anesthesia? In this article, we will shed some light on what happens during anesthesia, what different kinds of anesthesia exist and how they work.

Chances are, you know someone that had an operation. Nearly everyone needs one at some point during their life. Ask them if they 
Figure 1

Setup and monitoring during an operation. (A) An intravenous (IV) line is a little tube through which medication can be given directly into the blood. (B) The heartbeat is measured with stickers on the chest (green line on monitor); oxygen in the blood with a finger clip (blue line), and blood pressure with an inflatable cuff around the upper arm (white numbers). (C) The blue cloth separates the surgery area from the work area of the anesthetist. Fluids and other medication are given through an IV line. An airway device allows the breathing machine to pump air into the patient's lungs. An air warmer keeps the patient warm. General anesthetics are given through the breathing machine if they are a gas, or through the IV line if they are liquid.

\section{REGIONAL}

\section{ANESTHESIA}

A drug-induced numbness of certain body parts, such as an arm or leg, where the nerves are blocked in a way that they cannot transmit any movement or feelings of pain. In contrast to general anesthesia, the patient is awake and can remember everything.
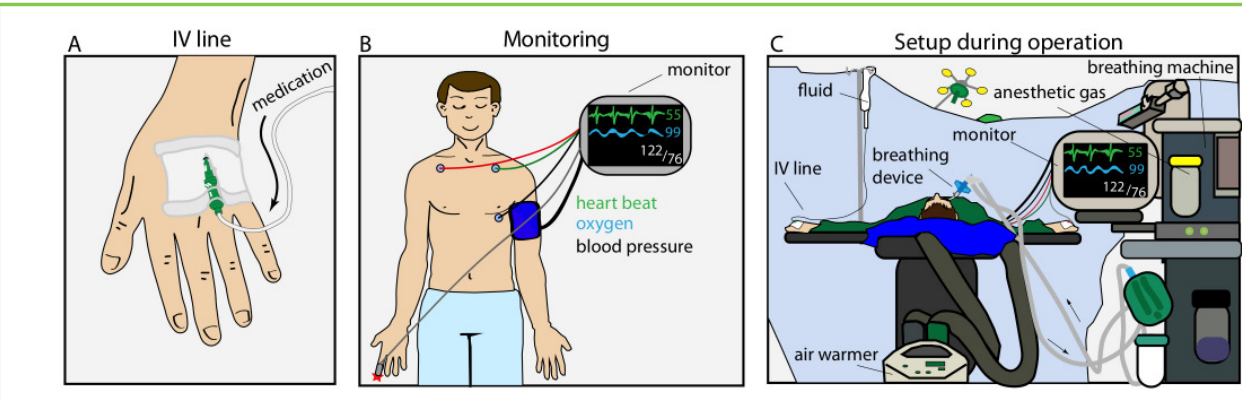

Figure 1

remember anything from the operation. Most likely they will recall some details about the time shortly before the operation, for example how they had to wear a silly nightgown. But at some point, they will not be able to remember what happened next-everything just turned black. At this moment, he or she was under anesthesia. But what exactly is anesthesia and how does it work? There are two main forms-one is called regional anesthesia because only one region of the body is under anesthesia, and the other is called general anesthesia because it affects the whole body.

\section{GENERAL ANESTHESIA AFFECTS THE WHOLE BODY}

Let us pretend that you have something in your tummy that needs an operation. Maybe you need to have your appendix removed, for example. For that kind of surgery, you will probably need general anesthesia. On the day of surgery, you will be taken into the operating room. The anesthetist will put a little tube called an intravenous (IV) line into a blood vessel-probably on the back of your hand (Figure $1 \mathrm{~A}$ ). Through that line, some fluid and all the medications required during the operation will enter your body. You will get three stickers on your chest to check your heart, a cuff around your arm to measure your blood pressure, and a clip with a red light attached to one of your fingers to measure the oxygen level in your blood (Figure 1B). Next, you will receive the anesthetic medication, either by breathing it in through a mask or receiving it through your IV line. Soon after, you will remember nothing more until you wake up after surgery.

While you are anesthetized, a lot of things go on. General anesthesia works on the whole brain-it blocks your ability to feel pain, it prevents movement, and it stops the formation of new memories [1]. Importantly, general anesthesia also affects other body functions, such as breathing, swallowing, body temperature, and blood pressure that are essential for life. Therefore, the anesthetist becomes something like the pilot of the patient and must take over all these functions, with the help of drugs and machines: Because you will stop breathing on your own under general anesthesia, the anesthetist will insert a small device into your throat to attach you to a breathing machine. 
GENERAL

ANESTHESIA

A drug-induced state that affects the whole brain, in which the patients does not experience his surroundings, does not feel any pain, move or form any memories. Other body functions, such as breathing are also affected by the drugs.

\section{APPENDIX}

A little tube-shaped part of the bowel that often gets infected.

\section{ANESTHETIST}

A doctor with special training in anesthesia.

\section{INTRAVENOUS (IV)}

Literally translates to "in-the-vein." IV lines are used to provide patients with fluids and medicines.

\section{ETHER}

A gas that makes people sleepy and insensitive to pain.

\section{UNCONSCIOUSNESS}

A state in which a person does not feel or experience anything that is going on around him/her.
This machine pushes a mixture of air and oxygen into your lungs. In addition, the anesthetist will also connect your mattress to an air warmer, so you do not get cold during surgery. The setup in the operation room looks similar to the cockpit of an airplane (Figure 1C).

At least two different types of drugs are used for general anesthesia-a pain killer and a general anesthetic that keeps you from experiencing or remembering anything. Sometimes the anesthetist will also use other medications, maybe to prevent you from moving or to keep your heart rate and blood pressure within the normal range. There are two big groups of general anesthetics, gasses, or fluids. Anesthetic gas will be given trough a mask. When you breathe in, it floats from your lungs into your blood and then travels to your brain. Over 200 years ago, people inhaled a gas called ether at home, for the same reasons people drink alcohol today. Doctors realized that, under the influence of ether, people did not seem to notice when they hurt themselves. This gave doctors the idea to use ether during operations. The first official demonstration of ether as an anesthetic was done at the Massachusetts General Hospital in Boston in 1846 [2], and this is still considered to be the founding moment of modern anesthesia. Since then, ether has been improved and newer versions are still widely used nowadays. The other group of general anesthetics are fluids that can be administered directly into the blood trough an IV line, and then travel to the brain. No matter which group is used, as long as the anesthetist continues to give you the general anesthetic, you will remain unconscious. During surgery, the anesthetist will stay with you the entire time, continuously check on you, and see if anything needs to be adjusted. When the operation is finished, the anesthetist will stop the medication and you will start to wake up. During that time, the anesthetist lets your brain and body slowly take over all their functions again and makes sure that you are safe. Afterwards, you may feel a little drowsy until the medication completely wears off. During this time, other doctors and nurses will look after you and make sure you are well.

\section{WHAT HAPPENS IN THE BRAIN UNDER GENERAL ANESTHESIA?}

When you are awake, your brain gets a lot of information about your surroundings through your senses-you see, hear, feel, smell, and touch. All this information is sent around between the different regions of your brain in a lively, seemingly chaotic way-like the animated chatter between students when no teacher is present (Figure 2A). Brain cells use electrical signals to talk to each other. General anesthetics block the brain cells in such a way that they cannot send signals to their neighbors anymore. If enough cells are kept from signaling their neighbors, the whole communication system between brain regions shuts down. The electrical brain signals suddenly become very 


\section{Figure 2}

General Anesthesia. (A) In the awake brain, there is communication between all the brain regions. The electrical brain waves may look chaotic, but they contain a lot of information. The four children represent brain regions doing different things but interacting with each other. (B) Under general anesthesia, communication between brain regions is reduced to a minimum, and the brain waves are very ordered. The children representing the brain regions all sing the same song and have stopped interacting with each other.

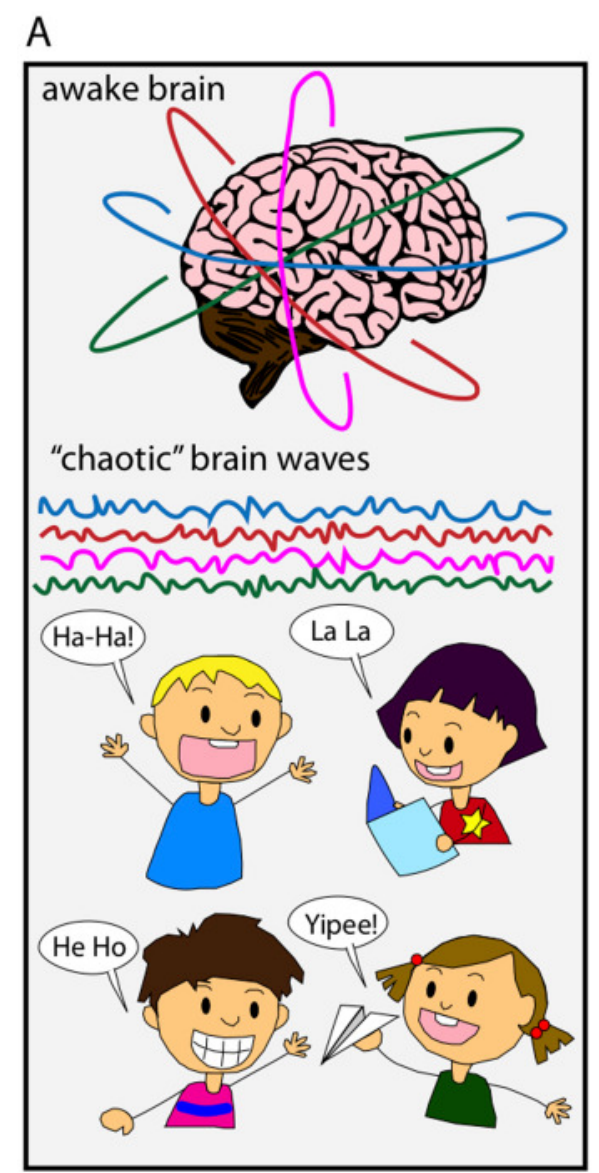

\section{B}

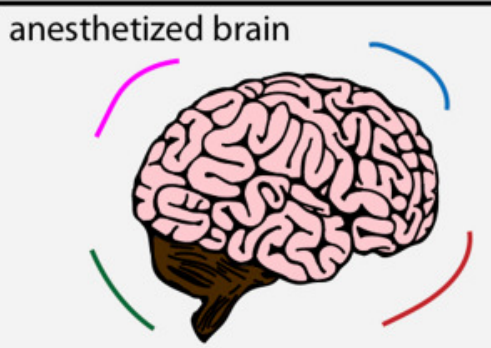

ordered brain waves

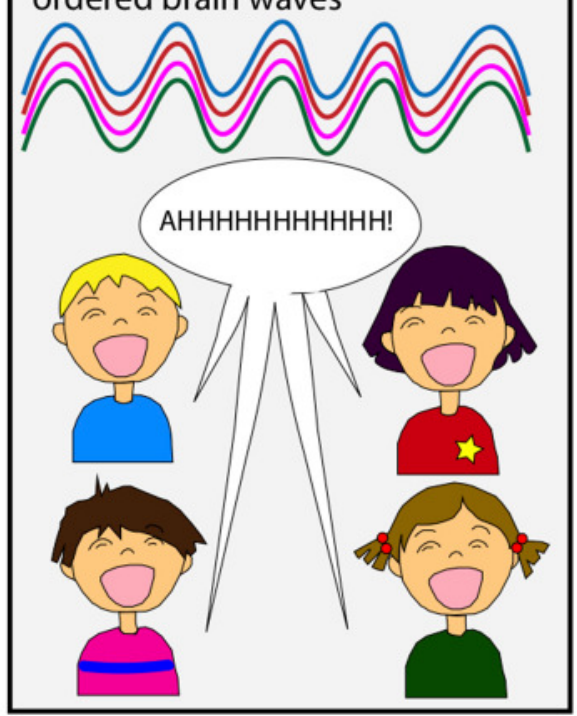

Figure 2

ordered-like a choir, the brain regions all start to chant the same song and do not talk to each other anymore ([1]; Figure 2B).

\section{ARE GENERAL ANESTHESIA AND SLEEP SIMILAR?}

Both during sleep and under general anesthesia, you are disconnected from the world. You do not interact with your surroundings and you do not notice anything that is going on around you. But although both states look similar from the outside, anesthesia is quite different from sleep. Sleep occurs naturally every night, whereas anesthesia is an artificial, drug-induced state. While your parents can wake you up from sleep, they could not wake you from anesthesia. And remember that anesthesia also affects breathing, body temperature, and blood pressure, while during sleep those functions are normal. Your brain functions are also different between sleep and anesthesia. Although it looks like you are not doing much when you are asleep, your brain is busy during the night. Many brain regions are active and talk to each other, reviewing all the new experiences and all the things you learnt during the day. Under anesthesia, all brain regions remain relatively silent and do not talk to each other. This also means that we do not get the benefits of sleep when we are under anesthesia. 
Figure 3

Regional Anesthesia (A) Nerves connect the brain with the whole body. Signals travel back and forth between the brain and the body using these electrical highways. An anesthetist can block the nerve of a specific region with the help of a syringe. Once blocked, signals from the brain, such as those that cause movement, cannot reach this region. In addition, signals that come from that region, such as pain signals, cannot reach the brain. (B) Close-up: A nerve is similar to a cable and contains many smaller bundles, like wires.

\section{NERVE}

Bundles of cells, like wires, that connect brain cells with cells outside of the brain. Electrical signals travel back and forth between the brain and the body along nerves.

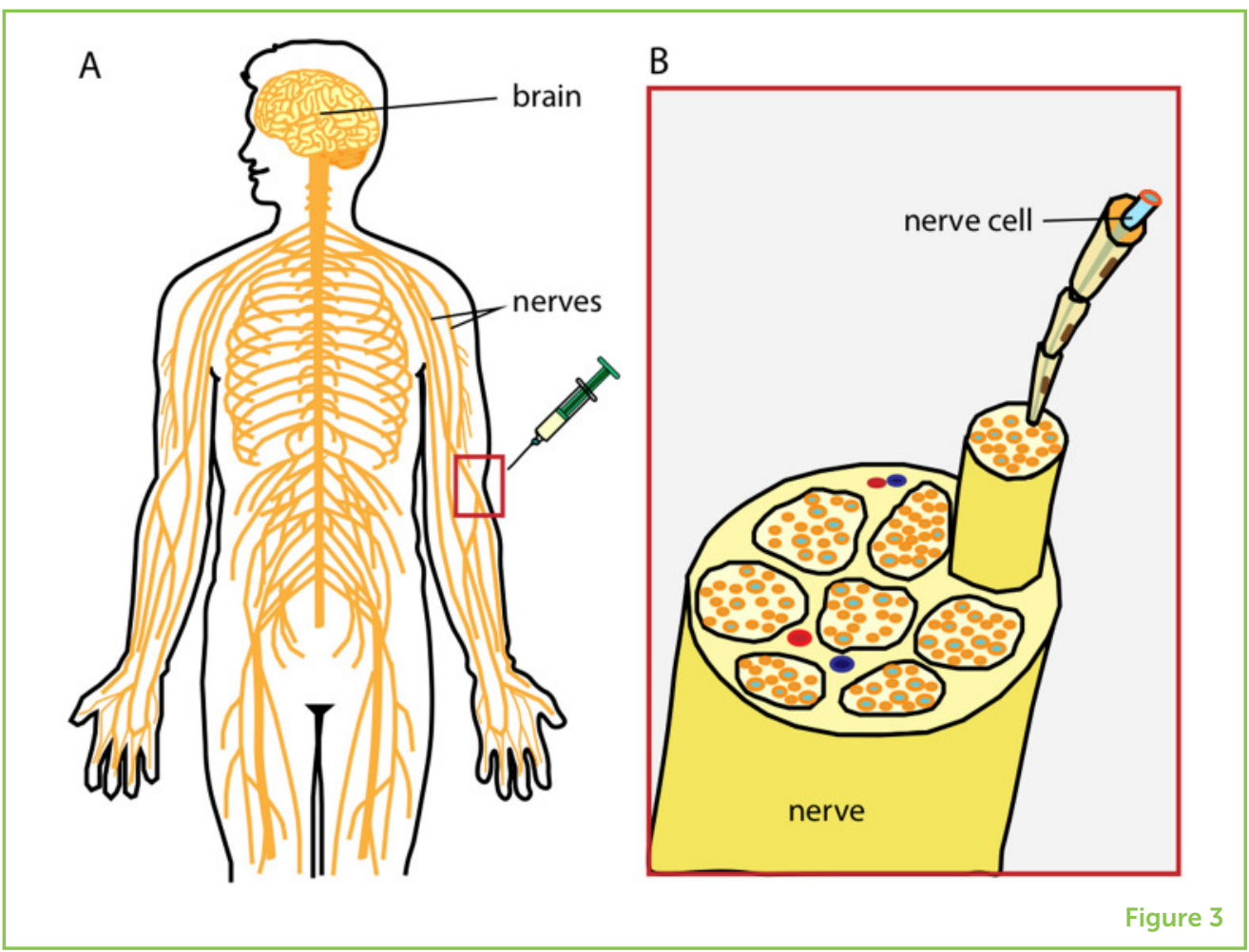

\section{REGIONAL ANESTHESIA NUMBS A CERTAIN BODY PART}

People are not always unconscious when they have anesthesia. If local or regional anesthesia is used, you can be fully awake and still not feel any pain from the surgery. For example, let us pretend that you accidentally cut your finger while using a knife. Ouch, that hurts! The electrical signal of pain travels quickly from your finger to your brain, along wire-like bundles called nerves (Figure 3A). Although pain is unpleasant, it is also an extremely important warning signal that causes you to pull your finger immediately away from the knife.

When a local anesthetic is injected close to a nerve (Figure 3B), this medication blocks the travel of the electrical signal to the brain. If only a small area of tissue is numbed, the procedure is called local anesthesia and can be performed by any doctor, for example the dentist. During regional anesthesia, a larger part of the body is numbed, mostly arms or legs. This needs to be done by an anesthetist, who decides depending on the type of operation, where to block the nerves-sometimes only a finger needs to be numbed, other times the whole hand or even the whole arm. Occasionally people receive additional medication during regional anesthesia to help them relax or fall asleep during the operation. Interestingly, the oldest local anesthetic was cocaine, a substance extracted from the leaves of the coca tree [3]. Cocaine was used as cough drops because it numbed the throat. But it was soon evident that it also caused a major problem: people became very addicted to it! Since then, scientists created 
modern drugs by changing some parts of the cocaine molecule so that it still numbs pain but is no longer addictive.

\section{CONCLUSION}

Anesthesia is one of the greatest discoveries of modern medicine-it made operations painless for patients. New surgeries were possible that would have been too traumatic to perform on an awake person. Today, many people every day get anesthesia for various reasons-at the dentist, for an operation at the hospital or a diagnostic procedure. Chances are, if you have not already, you will get anesthesia at least once in your life. However, anesthesia can also be risky in the wrong hands, as it affects all body functions including essential ones, such as breathing. Therefore, it is important that a trained anesthetist with good equipment looks after you during anesthesia. Like flying an airplane, anesthesia can be dangerous and complicated, but is also very safe when done correctly.

\section{REFERENCES}

1. Brown, E. N., Lydic, R., and Schiff, N. D. 2010. General anesthesia, sleep, and coma. N. Engl. J. Med. 363:2638-50. doi: 10.1056/NEJMra0808281

2. Bovill, J. G. 2008. Inhalation anaesthesia: from diethyl ether to xenon. Handb. Exp. Pharmacol. 182:121-42. doi: 10.1007/978-3-540-74806-9_6

3. Redman, M. 2011. Cocaine: what is the crack? A brief history of the use of cocaine as an anesthetic. Anesthesiol. Pain Med. 1:95-7. doi: 10.5812/kowsar.22 287523.1890

SUBMITTED: 05 January 2020; ACCEPTED: 22 January 2021; PUBLISHED ONLINE: 17 February 2021.

EDITED BY: Marcel Ruiz-Mejias, Pompeu Fabra University, Spain

CITATION: Lendner JD (2021) What Is Anesthesia? Front. Young Minds 9:524571. doi: $10.3389 /$ frym.2021.524571

CONFLICT OF INTEREST: The author declares that the research was conducted in the absence of any commercial or financial relationships that could be construed as a potential conflict of interest.

COPYRIGHT @ 2021 Lendner. This is an open-access article distributed under the terms of the Creative Commons Attribution License (CC BY). The use, distribution or reproduction in other forums is permitted, provided the original author(s) and the copyright owner(s) are credited and that the original publication in this journal is cited, in accordance with accepted academic practice. No use, distribution or reproduction is permitted which does not comply with these terms. 


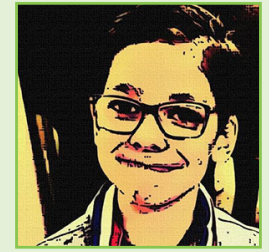

\section{YOUNG REVIEWER}

\section{MARCEL, AGE: 10}

I love science and math, and I want to be a roboticist someday. I am on my school's basketball team, and in the evenings I learn taekwondo. I play the violin, and as many video games as my mom will let me.

\section{AUTHOR}

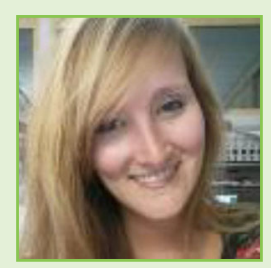

\section{JANNA D. LENDNER}

I am a neuroscientist at the University of California in Berkeley, which is so close to San Francisco that we can see the Golden Gate Bridge. Here, I study what happens to our brains when we are under anesthesia or when we sleep. I feel very fortunate to take part in the exciting research about the big mysteries of the human mind-what is consciousness and why do we sleep? In addition to being a researcher, I am also an anesthetist. When I am not in the lab, I like to explore the beautiful nature of the United States, do yoga, and eat delicious food. *janna.lendner@gmail.com 